\title{
FORÇAS DE CORTE ORTOGONAL 90-0 EM TRÊS ESPÉCIES DE MADEIRA DE EUCALIPTO
}

\author{
Antônio Carlos Néri', Raquel Gonçalves ${ }^{2}$ \& Roger E. Hernandez ${ }^{3}$
}

\begin{abstract}
RESUMO
As forças de corte ortogonal são utilizadas no projeto das ferramentas de corte e dimensionamento da potência das máquinas que compõem uma serraria. As forças de corte variam com a espécie da madeira, com a direção das fibras e de corte, com a afiação da ferramenta e com outras variáveis relacionadas à madeira (densidade, umidade) e com a ferramenta de corte (ângulo de ataque, velocidade de corte, espessura e largura de corte). A revisão bibliográfica realizada indica que há poucos dados disponíveis sobre a potência requerida durante o corte ortogonal 90-0, principalmente das espécies de Eucalyptus. As variáveis estudadas foram ângulo de ataque, espessura de corte, densidade e orientação de corte (radial e tangencial). A otimização e melhoria da usinagem do eucalipto permitirá que esta madeira seja mais facilmente aceita no mercado brasileiro e de exportação.
\end{abstract}

Palavras-chave: processamento mecânico da madeira, forças de corte, Eucalyptus

\section{ORTHOGONAL 90-0 CUTTING FORCES FOR THREE SPECIES OF EUCALYPTUS}

\begin{abstract}
The knowledge of the orthogonal forces are important in the design of the cutting tools and in establishment of the power requirement for the sawmill. The cutting forces varied according to the wood species, fibre and cutting direction, tool sharpness, wood properties (density, moisture content) and tool design characteristics (rake angle, cutting velocity, chip thickness, and wear). The review of literature shows that there is little data available about the power requirement during the $90-0$ orthogonal cut, especially for the Eucalyptus species. The variables analyzed in this study were rake angle, cutting thickness, wood density and orientation (radial e tangential). The optimization and improvement of the cutting process in Eucalyptus will permit acceptance of wood of these species in the Brazilian market and promote exports.
\end{abstract}

Key words: wood processing, cutting force, Eucalyptus

\section{INTRODUÇÃO}

A madeira de pinus e eucalipto usada em reflorestamento no Brasil, está adquirindo importância econômica cada vez maior.
Ainda assim, existem problemas relacionados à sua aceitação no mercado interno e de exportação. É necessário, portanto, conhecer-se as propriedades fisico-mecânicas dessas espécies antes de qualquer ação que pretenda promover a sua utilização

\footnotetext{
${ }^{1}$ Estudante de Pós-graduação da UNICAMP, Cidade Universitária Zeferino Vaz, s/n, CP 6011, Campinas, SP, Fone: (035) 821 3751, E-mail: acneri@agr.unicamp.br

${ }^{2}$ Prof. Dra., Faculdade de Engenharia Agrícola, UNICAMP, Fone: (019) 788 1044, Fax: (019) 788 1010, E-mail: raquel@agr.unicamp.br

${ }^{3}$ Prof. Ph.D., Faculdade de Ciências Florestais e da Madeira, Universidade de Laval/Québec, Canadá, Pavillon Abitibi Price G1K - 7P4 Université Laval Q.C Canadá. Fone: (418) 656 5852,E-mail: roger.hernandez@ sbf.ulaval.ca
} 
no mercado nacional e de exportação. Os diferentes estudos tecnológicos da madeira de reflorestamento têm-se direcionado às propriedades físico-mecânicas e ao estudo do comportamento à secagem. Os aspectos ligados à usinagem dessas espécies têm sido, muitas vezes, deixados de lado.

O processamento mecânico da madeira dessas espécies é ainda realizado de maneira empírica, em grande parte das serrarias, o que, em muitos casos, conduz a resultados inadequados e ineficientes, afetando diretamente a utilização racional deste recurso, além de limitar seu desenvolvimento e competitividade.

As espécies de eucalipto requerem técnicas de corte diferentes das normalmente utilizadas para espécies de coníferas, as quais requerem, geralmente, menor energia para o corte. Os eucaliptos são, muitas vezes, extremamente densos e, portanto, duros, pesados e resistentes. Estas características aumentam a energia requerida para processá-los e aceleram o desgaste das ferramentas de corte, das máquinas e do sistema de alimentação e transporte da madeira em uma serraria. Algumas dessas espécies possuem fibras reversas que dificultam o acabamento, enquanto outras apresentam tensões internas de crescimento, que produzem deformações ao longo do tronco e, também, em tábuas a medida em que se vai efetuando o corte. Essas tensões internas também ocasionam rachaduras nos extremos das toras, quando estas são amolecidas para o processamento de corte na produção de chapas laminadas.

Os danos produzidos pela secagem, como deformações e empenamentos, também dificultam o corte de peças planas e retas de madeira seca. O conhecimento dessas características é, portanto, muito importante para a utilização racional das diferentes espécies de eucalipto.

Um requisito básico para se determinar se uma espécie de madeira é adequada para um uso determinado, é o conhecimento e a análise de suas propriedades durante a usinagem. Estas características incluem serramento, desengrosso, torneamento, lixamento e furação. Algumas dessas operações podem ser encontradas no processamento primário e outras principalmente no processamento secundário da madeira. Todos esses tipos de corte envolvem um processo de tensão e ruptura; seja manual ou através de uma máquina, a força é transmitida à madeira através de uma ferramenta de corte, enquanto a orientação e a direção das forças são controladas segundo o tipo de ferramenta ou através das mãos do carpinteiro. A ferramenta tem, normalmente, geometria definida, e a madeira apresenta propriedades físicas e mecânicas próprias. A forma da ferramenta e sua direção de movimento determinam a maneira como os esforços se produzem e como estes são suportados pela madeira; conseqüientemente, o modo de ruptura.

As forças de corte requeridas têm grande importância no projeto da geometria da ferramenta de corte e na potência requerida das máquinas que compõem uma serraria. Estas forças de corte variam com a espécie de madeira, com a direção das fibras e de corte, com a afiação da ferramenta de corte e outras variáveis relacionadas com a matéria-prima e com a ferramenta.

O corte convencional é definido como a ação de uma ferramenta de corte em uma peça de madeira, a qual produz cavaco de dimensões variadas, cuja formação depende da geometria da ferramenta, da umidade da madeira e do movimento da ferramenta em relação à orientação das fibras. O objetivo da maioria dos processos de corte é a qualidade da peça de madeira produzida. A formação e a qualidade do cavaco não são, em muitos casos, objeto de atenção. Esses processos de corte incluem os realizados pela serra de fita, serra circular, desengrossadeiras, molduradoras, tupias, fresadoras etc. Em outros casos, tanto a peça de trabalho como o cavaco produzido são levados em conta como, por exemplo, no caso de tornos de laminação, esquadrejadora-picadora etc.

O corte ortogonal é definido como sendo a situação em que o fio da ferramenta de corte é perpendicular à direção do movimento relativo da ferramenta e da peça de madeira e quando a superfície obtida é paralela àquela antes do corte. Máquinas como a serra de fita, serra circular, tornos e plainas, podem ser estudadas utilizando os princípios do corte ortogonal. Mackenzie (1960) propôs uma notação com dois numerais para definir as diferentes situações que podem apresentar-se durante o corte ortogonal da madeira. O primeiro número representa o ângulo entre o fio de corte da ferramenta e a fibra da madeira e o segundo indica o ângulo entre a direção de corte e a fibra da madeira. Esta notação define os três principais casos apresentados na Figura 1, cortes 90-0, 90-90 e 0-90. O tipo 90-0 é encontrado em processos de corte como os realizados pelas plainas, desengrossadeiras e, também, nos cortes de tábuas, na direção paralela às fibras. $\mathrm{O}$ trabalho da serra de fita é um típico caso de corte 90-90 e as forças de corte variam em função do tipo de corte. Normalmente, maiores forças de corte são requeridas para o corte 90-90 que para o 90-0. O tipo 0-90 requer menores energias para o corte (Koch, 1985). A Figura 2 indica as diferentes componentes das forças de corte medidas no presente trabalho.

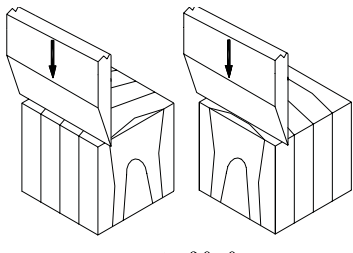

corte $90-0$

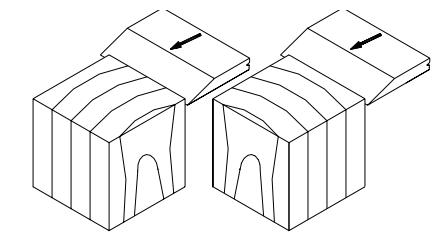

corte $90-90$

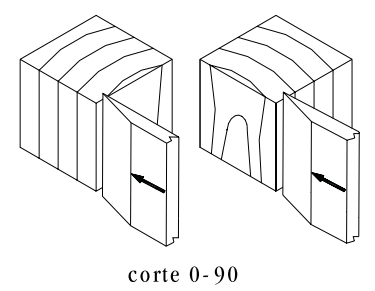

Figura 1. Principais tipos de corte ortogonal (Hoadley, 1980)

Existem vários métodos através dos quais se determinam as componentes das forças de corte durante o processamento da madeira. Gonçalves \& Ruffino (1995) apresentaram um método para medir essas forças em duas direções ortogonais: as componentes paralela $\mathrm{F}_{\mathrm{p}}$ e normal $\mathrm{F}_{\mathrm{n}}$ (Figura 2). Woodson (1979) utilizou um dinamômetro similar para avaliar o corte de 22 espécies de folhosas de zona temperada. Outros métodos permitem a medida simultânea das três componentes principais das forças de corte incluindo, neste caso, a componente lateral, e o dinamômetro construído por King \& Foschi (1969) é um exemplo deste caso. O instrumento consiste de dois anéis 


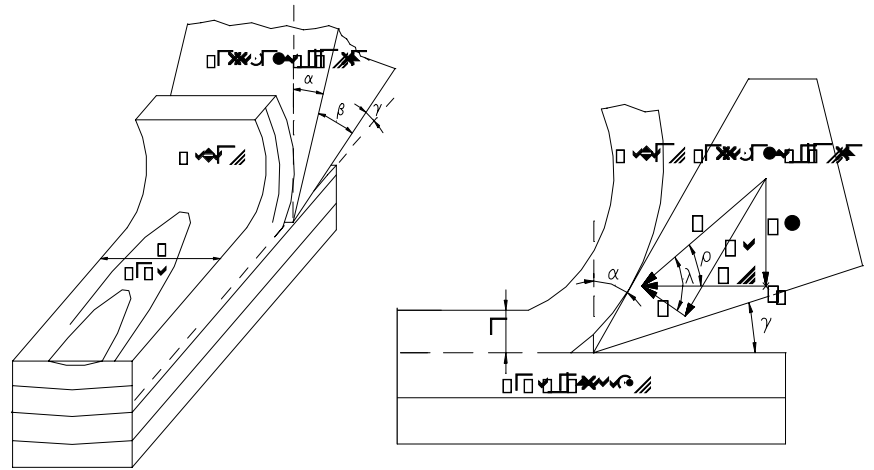

Figura 2. Ângulos de corte e componentes das Forças (Koch, 1985)

ortogonais providos de um sistema de 12 extensômetros, fixados de maneira tal que, teoricamente, nenhuma sensibilidade cruzada ou dependência sobre o ponto de aplicação da carga seja possível. Este tipo de dinamômetro foi utilizado neste trabalho.

A Figura 1 ilustra a situação na qual se apresenta o corte 90-0. Este tipo de corte ocorre, por exemplo, no aplainamento paralelo às fibras. A máquina de processamento de madeira mais comum, depois da serra, é a plaina, a qual trabalha em corte periférico mas na direção 90-0. A maior parte da madeira serrada normalmente é aplainada para eliminar defeitos, uniformizar as dimensões e melhorar a qualidade de corte. A qualidade da superfície e os tipos de defeitos de corte estão relacionados com o tipo de cavaco formado e, quando o corte é do tipo 90-0, observam-se três tipos básicos de cavaco. Franz (1958) definiu esses cavacos da seguinte forma:

Tipo I: o cavaco é formado à frente da aresta de corte da ferramenta; a primeira ruptura se dá por fendilhamento e o cavaco se separa da peça por ruptura a flexão, como uma viga engastada.

Tipo II: formado quando a ruptura da madeira se produz ao longo de uma linha que se estende a partir da aresta de corte da ferramenta; a ruptura se dá por cisalhamento diagonal e forma um cavaco contínuo. É o tipo de cavaco relacionado à melhor qualidade de superfície.

Tipo III: as forças de corte produzem ruptura por compressão paralela e cisalhamento longitudinal, diante da aresta da ferramenta de corte; o cavaco não tem forma definida e é reduzido a fragmentos.

Os tipos de cavaco são freqüentemente associados a um tipo particular de defeito produzido na superfície da madeira. A geometria da ferramenta, as propriedades da madeira e seu teor de umidade durante o corte, condicionam certos tipos de defeito.

O cavaco Tipo I está geralmente associado, ou pode ser produzido, quando a madeira apresenta baixa resistência a tração perpendicular e alta resistência a compressão paralela às fibras e à flexão. Um ângulo de ataque (a) elevado favorece a formação desse tipo de cavaco (Figura 2), principalmente quando este ângulo é maior que $25^{\circ}$ e o corte é realizado contra a fibra (Stewart 1971 ab). Grandes espessuras de corte também aumentam as possibilidades de formação desse tipo de cavaco. Tendo em vista que a ruptura ocorre por fendilhamento longitudinal, ela tende a seguir as fibras da madeira sendo, portanto, difícil controlar a qualidade do corte. Em muitos casos, esta ruptura ocorre abaixo do plano de corte, provocando o defeito conhecido como fibra arrancada.
O cavaco Tipo III pode provocar defeitos como fibra levantada ou superfícies com aspecto felpudo. Este cavaco é associado a ângulos de ataque pequenos ou negativos e com ferramentas pouco afiadas ou desgastadas. Estas situações provocam excessivas forças de corte, as quais aumentam a gravidade dos defeitos.

O cavaco Tipo II produz, geralmente, melhor qualidade de superfície. Para produzir este tipo de cavaco é necessário buscarse uma geometria adequada da ferramenta de corte para determinada espécie e de acordo com o teor de umidade da madeira a ser usinada. O cavaco Tipo II é formado, em geral, em condições intermediárias de corte com ângulo de ataque moderado e espessura de corte pequena (Koch, 1985).

\section{Corte ortogonal 90-90}

O corte 90-90 é de grande interesse prático considerando-se que é, por exemplo, realizado pela serra de fita de corte longitudinal (Koch, 1985). A aresta cortante da ferramenta separará o cavaco através de um corte longitudinal, o qual deve separar a estrutura celular na direção perpendicular à fibra. Durante sua formação, o cavaco sofre deformação por cisalhamento e rompe devido à flexão; posteriormente, ele desliza ou se move para fora da face de corte, formando uma espécie de cordão composto de pequenos segmentos retangulares (Hoadley, 1980). Tendo-se em vista que a ferramenta de corte deve separar as fibras perpendicularmente, um pequeno ângulo de ataque deverá deformar drasticamente a madeira, em compressão perpendicular às fibras durante o corte. Um efeito similar se produz quando a ferramenta não está bem afiada, cujas condições favorecem para que as fibras não sejam completamente cortadas e que, sendo flexionadas na superfície de corte, provoquem fendilhamento abaixo do plano de corte; por esta razão, recomenda-se o uso de grandes ângulos de ataque e ferramentas bem afiadas, pois estas condições minimizam os danos superficiais na peça, causados pelo corte (Mackenzie, 1960; Hoadley, 1980).

O corte longitudinal da serra de fita é um caso especial de corte 90-90. A fita é mais estreita que a peça a ser cortada e, desta forma, o dente deve separar e cortar as faces laterais para poder passar livremente dentro da ranhura de corte. Para evitar o atrito entre a serra de fita e as superfícies laterais de corte, os dentes devem ser mais largos na ponta; esta configuração recebe o nome de trava, cuja espessura deve ser maior que a espessura da fita.

Nos casos das serras circulares, a condição de corte se aproxima ao tipo 90-90 quando o disco corta o mais próximo possível de sua parte central. Quando se muda a serra ela é ajustada para fazer um sulco (ranhura) raso, seus dentes trabalham em uma situação de corte próximo ao tipo 90-0 (Hoadley, 1980).

Uma análise da literatura mostra que não há muita informação disponível sobre as forças requeridas para o processamento das diferentes espécies de eucalipto no Brasil. O objetivo deste trabalho foi avaliar as forças de corte ortogonal 90-0 das espécies de Eucalyptus grandis, Eucalyptus saligna e Eucalyptus citriodora. As variáveis ângulo de ataque, espessura de corte, densidade, direção de corte e orientação (radial e tangencial) foram avaliadas em relação às forças de corte. 


\section{MATERIAL E MÉTODOS}

As espécies Eucalyptus grandis, Eucalyptus saligna e Eucalyptus citriodora foram selecionadas com o objetivo de abranger um intervalo de densidades que permitam classificálas dentro de três das quatro classes de resistência da norma NBR-7190/96 (ABNT, 1996):

- dinamômetro de anéis ortogonais, proposto por King \& Foschi (1969)

- fresadora provida de mesa com movimento vertical e horizontal

- carta de aquisição de dados Strawberry mini-16, conectada a um computador PC

- facas e dentes adaptados aos diferentes ângulos estudados

Dezesseis peças de $150 \times 150$ × $1000 \mathrm{~mm}$ foram cortadas, procedentes de três árvores das espécies estudadas. As árvores foram obtidas no horto-florestal de Itirapina, Rio Claro, SP, e cortadas no Laboratório de Madeiras e Estruturas de Madeiras da Escola de Engenharia de São Carlos (LAMEM). As peças foram tratadas com produto anti-fúgico, embaladas com plástico e enviadas à Universidade Laval, Canadá. Os corpos de prova para a medida das forças de corte, na direção 90-0 e 90-90 e densidade, foram retirados adjacentes, de acordo com o esquema mostrado na Figura 3. Esses corpos de prova foram retirados segundo dois tipos de orientação: tangencial e radial. As dimensões dos corpos de prova foram de $6 \mathrm{~mm}$ (direção radial ou tangencial) por $75 \mathrm{~mm}$ (direção radial ou tangencial) por 75 mm (longitudinal). A madeira foi conservada no estado verde durante os ensaios de força de corte e densidade.

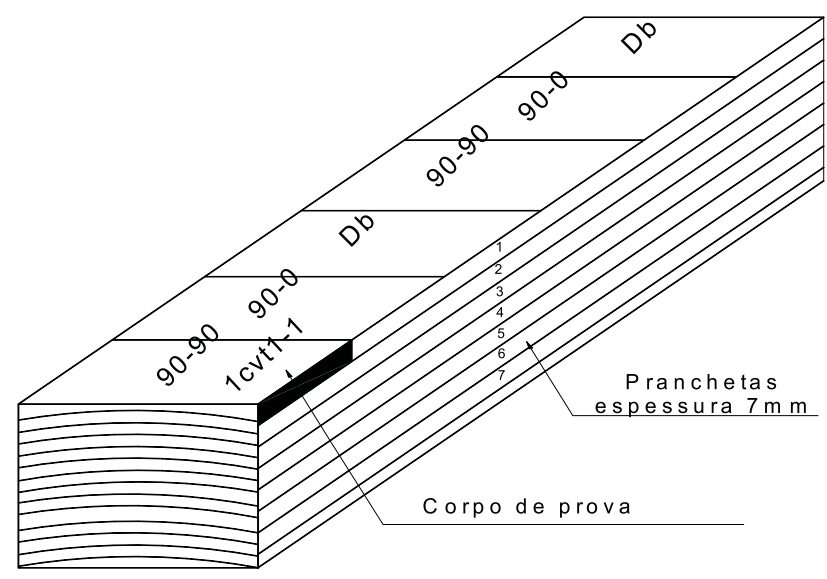

Figura 3. Exemplo de preparação de corpos de prova de orientação tangencial

\section{Medida das forças de corte}

As forças de corte foram medidas nas direções 90-0 e 90-90. No presente trabalho somente são apresentados e discutidos os resultados do corte 90-0. Os ensaios foram realizados empregando-se quatro espessuras de corte: 0,38, 0,76, 1,14 e $1,52 \mathrm{~mm}$ e três ângulos de ataque $\mathrm{a}=10^{\circ}, 20^{\circ} \mathrm{e} 30^{\circ}$. A velocidade de corte foi de $30 \mathrm{~mm} / \mathrm{min}$. Duas passadas consecutivas foram feitas para cada espessura de corte, com a finalidade de se estimar melhor o valor médio. Durante cada corte avaliaram-se o tipo de cavaco e a qualidade da superfície obtida. As forças eram registradas simultaneamente durante o ensaio, nas três direções principais: paralela $\left(\mathrm{F}_{\mathrm{p}}\right)$ normal $\left(\mathrm{F}_{\mathrm{n}}\right)$ e lateral $\left(\mathrm{F}_{1}\right)$ utilizando-se carta de aquisição de dados, que registrava 25 leituras por segundo. Um exemplo de registro é apresentado na Figura 4. Com os dados obtidos, foi calculado o valor de força máxima de corte, média e mínima para cada ensaio.

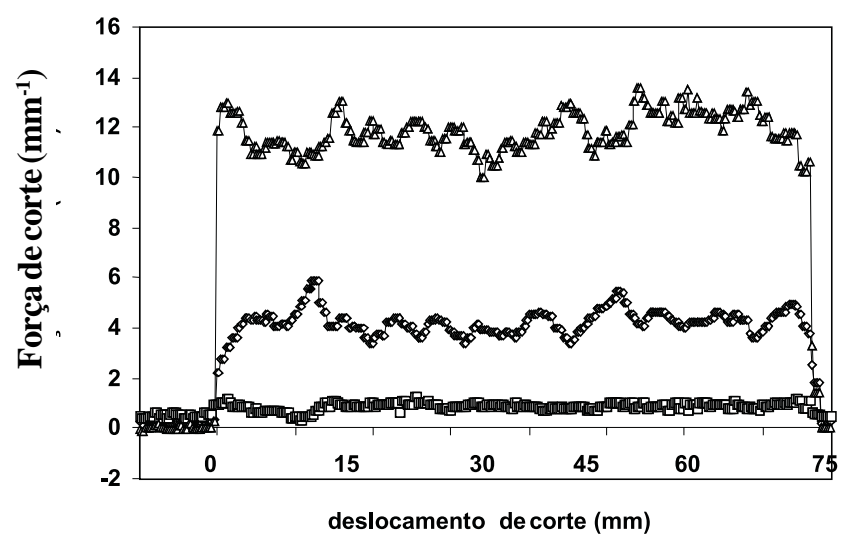

- - força normal $\quad=\leftarrow$ força lateral $\quad=4$ força paralela

Figura 4. Exemplo de registro do gráfico com a carta de aquisição de dados

\section{Determinação da densidade e umidade da madeira}

Corpos de prova adjacentes àqueles utilizados para o ensaio de corte serviram para determinar a densidade e o teor de umidade da madeira. $\mathrm{O}$ volume no estado saturado do corpo de prova foi determinado pelo método de imersão em água desionizada, medindo-se seu peso em uma balança de $0,01 \mathrm{~g}$ de precisão. A massa seca foi obtida após secagem em estufa a $103 \pm 2^{\circ} \mathrm{C}$, por um período de $24 \mathrm{~h}$, utilizando-se balança de precisão $0,001 \mathrm{~g}$. A densidade básica foi calculada pela razão massa seca/volume saturado.

\section{RESULTADOS E DISCUSSÃO}

O teor de umidade da madeira variou de $81 \%$ a $120 \%$ no Eucalyptus grandis, de $63 \%$ a $99 \%$ no Eucalyptus saligna e de $35 \%$ a $47 \%$ no Eucalyptus citriodora. As forças de corte correspondem, então, ao estado verde. A densidade básica foi de $0,415 \mathrm{~g} \mathrm{~cm}^{-3}$ para o Eucalyptus grandis, de $0,564 \mathrm{~g} \mathrm{~cm}^{-3}$ no Eucalyptus saligna e de $0,912 \mathrm{~g} \mathrm{~cm}^{-3}$ no Eucalyptus citriodora. Esta grande amplitude dos valores de densidade possibilita o estudo do estabelecimento de equações para se predizer as forças de corte em função da densidade da madeira. Estas relações seriam de muita utilidade para extrapolar os resultados para outras espécies de eucalipto.

Os valores de forças de corte foram sumarizados em quadros, os quais apresentam os valores médios em $\mathrm{N} \mathrm{mm}^{-1}$ da força de corte normal, lateral e paralela para cada condição de corte. Estas condições incluem três espécies de eucalipto, três ângulos de ataque, quatro espessuras de corte e duas orientações do corpo de prova. Cada uma das condições de corte foi realizada com 20 repetições (corpos de prova).

Os resultados para o corte 90-0 demonstram que o ângulo de ataque e a espessura de corte afetam diretamente a formação do cavaco produzido. Os três tipos básicos de cavaco foram observados dependendo das condições de corte utilizadas. 
A melhor qualidade de superfície de corte foi geralmente associada à formação do cavaco Tipo II. Tendo em vista os modos de ruptura na madeira, os quais estão ligados aos tipos de cavaco formados, os modelos físicos que se empregam geralmente consideram a madeira à frente da ferramenta de corte, como sendo uma viga engastada em equilíbrio um instante antes da ruptura (Franz, 1958; Mckenzie, 1960; Stewart, 197a). As forças que se desenvolvem na peça de madeira, de onde o cavaco é cortado, representam a reação ao movimento da ferramenta de corte. Esta reação é dada pela resistência ou interação das propriedades mecânicas da madeira durante o corte.

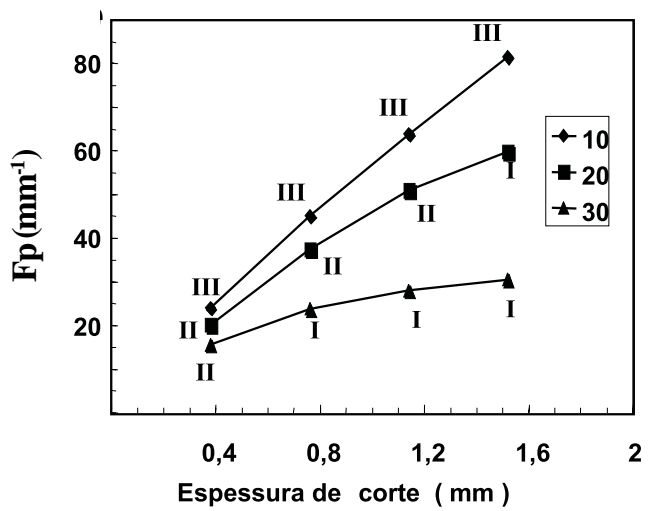

Figura 5. Força paralela média no corte $90-0$ em função da espessura de corte e do ângulo de ataque. Corpo de prova tangencial de Eucalyptus citriodora

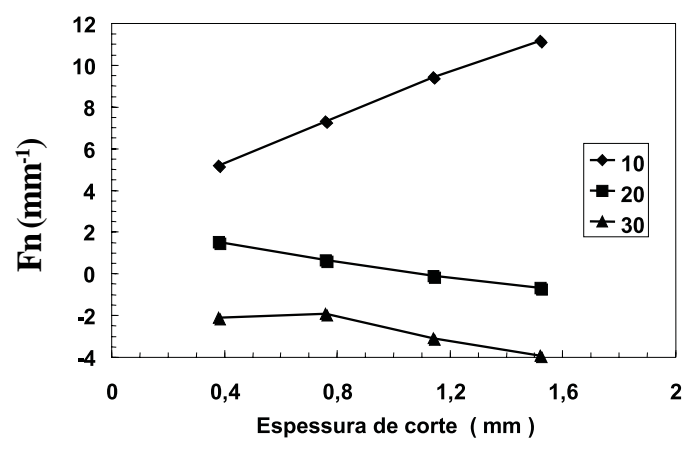

Figura 6. Força normal média no corte 90-0 em função da espessura de corte e do ângulo de ataque. Corpo de prova tangencial de Eucalyptus citriodora

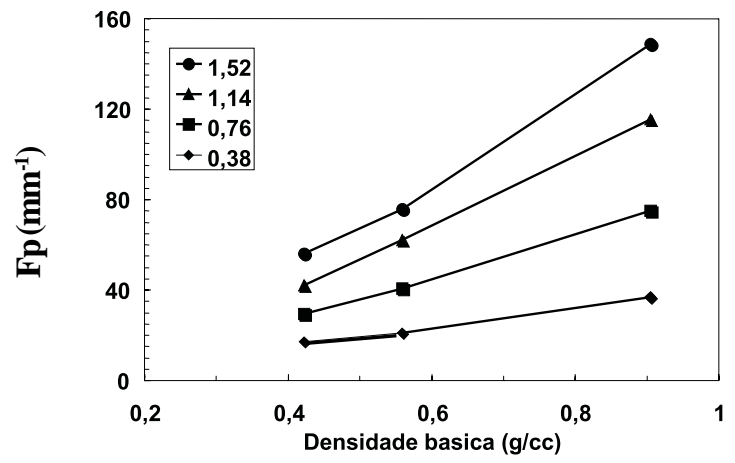

Figura 7. Força paralela média no corte 90-90 em função da densidade básica da madeira e da espessura de corte. Corpo de prova tangencial; $\alpha=30^{\circ}$
Por outro lado, gráficos foram construídos com a finalidade de se estudar a relação entre as forças de corte e a espessura de corte; entre as forças de corte e a densidade da madeira e, finalmente, entre as forças de corte e o ângulo de ataque. Exemplos desses gráficos são apresentados nas Figuras 5 a 7 e suas análises mostram que os valores das forças de corte tiveram tendência coerente. Observou-se que a força paralela aumenta com o aumento da espessura de corte (Figura 5) e da densidade da madeira (Figura 7); entretanto, a relação não é sempre linear, pois depende do tipo de cavaco formado, o qual varia em função da espessura de corte (Figura 5), do ângulo de ataque a e da espécie de madeira (Figura 7). Observou-se, também, que a força paralela diminui com o aumento do ângulo de ataque, sendo o efeito do ângulo maior a medida em que a espessura de corte aumenta (Figura 5). Em uma etapa posterior, uma análise mais detalhada de regressão linear será realizada para se estudar a relação entre os diferentes fatores que afetam as forças de corte.

O efeito da espessura de corte na força normal foi dependente do ângulo de ataque utilizado (Figura 6). Esta força aumentou e, inclusive, mudou de direção ou sinal, a medida em que o ângulo de ataque aumentou, ou seja, a força passou de positiva a negativa entre os ângulos de ataque $20^{\circ}$ e $30^{\circ}$ para Eucalyptus saligna e Eucalyptus citriodora. A força normal média foi sempre positiva para Eucalyptus grandis para todos os ângulos e espessuras estudados. Um sinal positivo da força normal indica que a ferramenta tende a comprimir ou pressionar a peça de madeira e um sinal negativo indica que esta tende a sair da peça (Figura 2).

A magnitude e a variação do sinal da força normal estão relacionadas aos tipos de cavaco formados, tal como estabelece Stewart (1977). Este autor analisou os três tipos básicos de cavaco e observou que uma força normal negativa com grandes ângulos de ataque está associada ao cavaco Tipo I, forças normais positivas de pequena magnitude e com ângulos de ataque intermediários estão associados ao cavaco Tipo II e forças normais positivas de grandes magnitudes, com pequenos ângulos de ataque, estão associados ao cavaco Tipo III. Tendo em vista que a força normal associada ao cavaco do Tipo II é pequena, Stewart (1977) sugeriu que uma força normal próximo de zero deveria ser responsável pela formação do cavaco Tipo II em um corte ortogonal paralelo às fibras. Com base nisso, ele propôs um método para estimar o ângulo de ataque ideal para a formação do cavaco Tipo II; este ângulo é baseado na relação entre a força normal, a força paralela e o coeficiente de atrito durante o corte e a técnica pode ser aplicada para selecionar uma geometria apropriada da ferramenta de corte em situações práticas. Valores de forças de corte medidos nos ensaios experimentais efetuados neste trabalho podem ser utilizados para a proposição de ângulos de ataque ideais para as três espécies de eucalipto estudadas. As correlações entre as forças de corte e as classes de densidade encontram-se em estudo, podendo servir para se estimar os valores para outras espécies de eucalipto.

\section{CONCLUSÕES}

Análise preliminar dos resultados deste trabalho conduziram às seguintes conclusões:

1. A melhor qualidade de superfície de corte foi geralmente coincidente com a formação do cavaco do Tipo II. 
2. Relações obtidas entre a força de corte e a espessura de corte e entre a força de corte e a densidade, não tiveram comportamento linear em todos os casos.

3. A força de corte paralela aumenta com o aumento da espessura de corte. Este efeito aumenta com a diminuição do ângulo de ataque.

4. A força de corte paralela diminui com o aumento do ângulo de ataque.

5. Em geral, a força de corte paralela aumenta com o aumento da densidade. A magnitude deste efeito depende do ângulo de ataque utilizado.

6. O efeito da espessura de corte na força normal depende do ângulo de ataque utilizado.

7. Nos corpos de prova de orientação tangencial e radial de Eucalyptus grandis, a força normal média foi positiva para todos os ângulos e espessuras de corte. Uma força normal positiva indica que a ferramenta tende a comprimir ou pressionar a peça de madeira.

8. Para o Eucalyptus saligna e Eucalyptus citriodora, a força normal média passou de positiva a negativa (ferramenta de corte saindo da peça de madeira) entre os ângulos de ataque de $20^{\circ}$ e $30^{\circ}$, tanto para os corpos de prova de orientação tangencial como para os de orientação radial.

\section{REFERÊNCIAS BIBLIOGRÁFICAS}

FRANZ, N.C. An analysis of the wood-cutting process. Ann Arbor. Univ. Michigan, 1958, 152p. Ph.D. Thesis.

GONÇALVES, M.T.T. Proposta de metodologia para medição dos esforços de corte na usinagem da madeira. São Carlos: EESC/USP. 1993, 249p. Tese Doutorado

HOADLEY, R.B. Understanding wood. A Craftsman's Guide to Wood Technology. The Taunton Press, p.256, 1980.

KING, B.; FOSCHI, R.O. Crossed-Ring dynamometer for direct force resolution into three orthogonal components. International Journal of Machine Tool Design Research. v. 9, p. 345-356, 1969.

$\mathrm{KOCH}, \mathrm{P}$. Utilization of hardwoods growing on southern pines sites. Volume II. Processing. USDA Forest Service, Agriculture Handbook, number 605. Chapter 18, Machining, 1985, p. 1687-2281.

McKENZIE, W.M. Fundamental aspects of the wood cutting process. Forest Products Journal, v. 10, n. 9, p.447-456, 1960.

STEWART, H.A. Chip formation when orthogonally cutting wood against the grain. Wood Science, v. 3, n. 4, p.193-203,1971a.

STEWART, H.A. Rake angle for planing hard maple determined best by depth of chipped grain - USDA Forest Service, Research Note NC-92, 1971b, 4p.

STEWART, H.A. Optimum rake angle related to selected properties of wood. Forest Products Journal, v. 27, n. 1, p.51-53, 1977. 